Resenha

\title{
Conservadorismo e atualidade
}

Sidnei Ferreira de Vares $^{1}$

Resenha do livro:

COUTINHO, J. P. As ideias conservadoras: explicadas a revolucionários e reacionários. 1. ed. São Paulo, Três Estrelas, 2014. p. 127.

João Pereira Coutinho é formado em História pela Universidade do Porto, doutor em Teoria e Ciência Política pela Universidade Católica Portuguesa, na qual atua como professor convidado. Entre suas publicações destacam-se Jaime e outros bichos e Avenida Paulista (2007). Iniciou mais tarde uma carreira na área jornalística como colunista d'O Independente (1998-2003), da revista Atlântico e do jornal Expresso (2004-2009). Atualmente é colaborador do Correio da Manhã e da Folha de S. Paulo (Brasil).

Seu livro As ideias conservadoras - explicadas a revolucionários e reacionários constitui um ensaio sobre o tema do conservadorismo, conquanto alguns temas secundários - a exemplo do pensamento reacionário e revolucionário - também estejam incorporados à sua análise. $\mathrm{O}$ texto divide-se em seis partes ou capítulos, além, é claro, da introdução, da conclusão e das referências bibliográficas, acrescido das notas (inseridas ao final do texto) e de um índice remissivo.

Logo na "Introdução" (Quattordici: uma introdução), o autor português atenta para o equívoco que é pensar o conservadorismo como uma ideologia unívoca. O que existe são "conservadorismos", no plural, visto que a ideologia conservadora se expressou diferentemente no tempo e no espaço. Aproveita para enfatizar que a análise empreendida tem como base o pensamento conservador moderno, em especial a obra do pensador irlandês Edmund Burke, com a qual demonstra afinidade, já que a obra do parlamentar britânico foi objeto de pesquisa de seu doutoramento. Isso, porém, não invalida as diversas menções e os diálogos feitos com outros autores identificados com o pensamento conservador antigo, moderno e contemporâneo. É também na introdução que Coutinho estabelece uma

${ }^{1}$ Centro Universitário Assunção (UNIFAI) - São Paulo - Brasil - vares@usp.br 
diferenciação importante: aquela entre "pensamento conservador" e o "pensamento reacionário". Esse é um passo fundamental para as pretensões de Coutinho, pois, à medida que o reacionarismo desponta como uma ideologia que visa restaurar 0 passado, espécie de estado de perfeição perdido, o conservadorismo apresenta-se como uma ideologia que atua sempre em relação ao presente, ao possível e ao real. Coutinho situa historicamente o conservadorismo moderno em oposição à Revolução Francesa de 1789. Por isso, em sua visão, o conservadorismo se define por seu caráter reativo, antirrevolucionário e antiutópico.

No primeiro capítulo, "A ideologia conservadora", Coutinho procura demonstrar que o conservadorismo, contrariamente ao que pensam alguns de seus representantes, não é um mero temperamento, instinto, inclinação ou disposição pessoal, mas, antes, uma ideologia. Claro, enquanto ideologia, o conservadorismo possui algumas características: ele é "reativo" e "posicional". Reativo, pois o agente conservador só se manifesta quando os valores e as instituições que ele julga dignas de conservação estão em risco. Posicional, pois se caracteriza por uma tomada de posição frente àquelas ideologias que defendem soluções utópicas, que apontam tanto para um passado glorioso quanto para um futuro incerto. Destarte, trata-se de uma "ideologia de emergência" que, segundo o autor, emerge todas as vezes em que os "fundamentos institucionais da sociedade" são ameaçados por algum tipo de ação radical. Sendo assim, o agente conservador não partilha nem da "felicidade utópica" típica da atitude revolucionária nem das concepções retroativas contidas no pensamento reacionário. Em termos políticos, os conservadores atuam sempre a partir do presente, tentando preservá-lo de transformações abruptas e violentas. Conquanto admitam as mudanças, essas são sempre calculadas, adquirindo uma roupagem reformista, mas nunca revolucionária.

No segundo capítulo, "Imperfeição humana", Coutinho, baseado numa ampla bibliografia conservadora, empreende uma crítica àquilo que considera ser uma das características das ideologias rivais (reacionárias e revolucionárias), a noção de perfeição humana. Distanciando-se da análise teológica, embora em consonância com seu conteúdo, o autor argumenta que os homens são intelectualmente imperfeitos e, sendo assim, é um erro acreditar que o presente pode ser substituído, seja por uma época de ouro ida (como defendem os reacionários), seja por um futuro hipoteticamente superior (como querem os revolucionários). Critica assim a crença, consolidada durante a Revolução Francesa, de que é possível modificar a realidade através da razão, o que considera uma posição arrogante e quimérica, visto que entre a idealização e a concretização repousa o imponderável. Nesse sentido, o conservador teria a vantagem da prudência e da humildade frente ao presente, à realidade, na medida em que suas ações são sempre guiadas pela consciência de sua imperfeição epistemológica e política.

No terceiro capítulo, "O sentido da realidade", o autor retoma a ideia de que o conservadorismo é uma ideologia posicional e reativa para, logo em seguida, reforçar a tese de que a realidade não é um espaço para aventureiros. Argumenta que o pensamento conservador, ao longo do tempo, mostrou-se válido devido 
ao fato de seus representantes admitirem a circunstância como um elemento crucial para a política. Destarte, em termos morais e políticos, os conservadores refutam qualquer elemento universal. As possibilidades da ação ficam assim circunscritas à realidade. Por conseguinte, o estadista conservador tende a ser maleável, pois a realidade é plural e cada circunstância convida a uma resposta particular. Isso não significa, entretanto, que os conservadores guiem-se apenas pelo sabor do momento. Sem linhas morais mínimas, o que o Coutinho denomina de "valores primários", nenhuma sociedade civilizada seria possível. "História", "tradição", "cultura" e "preconceito" são, arremata o autor, "esses quatro cavaleiros do apocalipse progressista", sem os quais a conduta política conservadora e racional não seria possível.

O quarto capítulo, "Os testes do tempo", talvez seja a parte mais importante deste trabalho, pois é aqui que Coutinho desmistifica a visão caricatural que recai sobre o pensamento conservador, a saber, aquela que entende o conservador como alguém arraigado às tradições e às instituições vigentes, e, por isso, incapaz de aceitar quaisquer mudanças. Para justificar sua posição, o autor enfatiza que as tradições ensinam o conservador a preservar, tanto em termos institucionais quanto em termos morais, aquilo que considera importante para a vida social. Em nenhum momento, porém, Coutinho se pergunta se a conservação de determinados valores e instituições - ainda que atestados pela história - é de fato justa, se beneficia ou não todos os grupos. Tem-se assim a impressão de que o simples fato de uma situação perdurar no tempo é suficiente para sustentá-la eticamente. Não custa lembrar que a escravidão foi uma prática que sobreviveu por séculos e que nem por isso era justa. O ponto alto do capítulo, todavia, repousa na perspectiva naturalista e evolucionista por ele adotada, segundo a qual a sociedade não dá saltos e que, por isso, qualquer transformação abrupta tende a romper com a ordem natural dos fatos. As tradições, desse ponto de vista, são pedagógicas e formativas, e exatamente por tais características, só podem ser reformadas, mas nunca radicalmente substituídas. Daí o autor defender o preconceito (os conceitos que precedem o surgimento de outros). Trata-se, pois, de entender as mudanças dentro de um escopo reformista, isto é, tuteladas pelo passado e pelo presente configurando uma posição eminentemente evolucionária de história.

No quinto capítulo, "A reforma prudente", Coutinho procura desconstruir a imagem do conservador como um imobilista, fatalista e pessimista. Segundo o cientista político português, esses adjetivos são por demais caricatos. Com vistas a defender sua posição, argumenta que o conservador, no que se refere à mudança, é um homem prudente, realista e pouco afeito aos riscos inerentes ao pensamento utópico. Para justificar sua posição, Coutinho procura desconstruir o cerne das críticas dirigidas ao pensamento conservador. Analisa, detidamente, as obras de dois opositores contemporâneos, Albert Hirschman (A Retórica da Reação) e Corey Robin (Mente Reacionária), com o objetivo de superar as críticas mais comuns em relação ao conservadorismo, a saber: (a) a de que, para os conservadores, toda ação revolucionária ou reformista necessariamente culminará em seu contrário; 
(b) a de que a mudança, na perspectiva conservadora, é sempre paliativa e superficial;

(c) a de que toda mudança para o conservador põe em risco as instituições e os valores instituídos. Assentado nas obras de Noël O'Sullivan e Benjamin Disraeli, dois importantes representantes do pensamento conservador contemporâneo, Coutinho defende que o conservador não é contrário a mudanças, porém estas sempre são feitas por referências (e em deferência) às maneiras, aos costumes, às leis e às tradições.

No sexto e último capítulo, "A sociedade comercial", Coutinho resgata alguns pressupostos do pensamento liberal, em especial aqueles presentes na obra de Adam Smith, visando superar as difíceis relações entre o conservadorismo e o capitalismo. Geralmente, atribui-se à esquerda as únicas críticas dirigidas ao livre mercado, entendido como corruptor da ordem social. Contudo, observa o autor, "[...] é possível escrever um longo manual anticapitalista só com autores conservadores e suas proclamações contra a sociedade comercial [...]" (Coutinho, 2014: 81). Assim, para uma parte substancial do pensamento conservador, a "sociedade comercial", ao reduzir as relações pessoais a critérios puramente econômicos, sem levar em consideração os aspectos mais nobres das relações humanas, mostra as feições mais desumanas e corruptoras do ser humano. Ademais, o livre-comércio também

[...] cria tensões e disrupções na sociedade tradicional, acarretando permanentes mudanças que colocam em risco princípios ou instituições que, apesar de terem sobrevivido aos testes do tempo, podem não resistir às destruições criativas de que a sociedade comercial é tão pródiga [...] (Coutinho, 2014: 82).

Essa, porém, não é uma posição assumida por todos os conservadores. Existem aqueles que, desde Burke, defendem que a "sociedade comercial" constitui um "sistema de liberdade natural" e que a atividade comercial, a permuta ou troca de uma coisa pela outra, "tem como objetivo fazer com que os indivíduos possam melhorar a sua condição". E, continua o autor,

[...] o conservadorismo, portanto, deve começar por respeitar a natureza dos homens. E isso significa observar a vontade destes em participar num sistema em que são as escolhas naturais e livres dos indivíduos, e não a imposição autoritária de um padrão único de preferências ou comportamentos, que devem ser soberanas [...] (Coutinho, 2014: 87).

Para garantir que essas relações se deem de modo justo e eficaz, Coutinho, ancorado em Adam Smith e assumindo como modelo de gestão da ex-primeira ministra britânica Margaret Tatcher, aponta o Estado como uma instituição fundamental, pois só ele pode garantir a defesa da paz e da ordem e a defesa da propriedade privada.

Na "Conclusão" (Conservadores ou monomaníacos: uma conclusão), Coutinho retoma as principais ideias exploradas no decorrer do trabalho. Enfatiza que o conservador longe de ser imobilista, reacionário, autoritário, fascista, é, pelo contrário, contra qualquer tipo de solução violenta. Disso decorre a principal 
diferença entre o conservador e o revolucionário, pois, enquanto este se assenta no "princípio de preguiça", já que ao invés de estudar e reformar o que é real opta por atalhos violentos, aquele se assenta no reconhecimento da falibilidade humana e, por suposto, empreende, em matéria de política, ações moderadas e prudentes, mas nunca guiadas por utopias. Em suma, afirma o autor, o conservador político acredita que "[...] o imperativo da continuidade é mais importante do que a promessa de que algo irá triunfar [...]" (Coutinho, 2014: 104).

A análise de Coutinho peca pela superficialidade. Em primeiro lugar, o autor é incapaz de notar que a violência não é um fenômeno exclusivo dos revolucionários. Ela está disseminada histórica e socialmente, de modo que mesmo os conservadores, por ele descrito como arautos dos valores humanos, também reproduzem práticas violentas (sejam estas físicas ou simbólicas). Em segundo lugar, o autor trata os "revolucionários" como um bloco unívoco, sem fazer uma distinção mais clara (tal como reivindica quando distingue "conservadores" e "reacionários") entre anarquistas, comunistas e socialistas, como se o fato de todos eles desejarem mudar a sociedade fosse suficiente para alocá-los numa mesma rubrica. Em terceiro lugar, a perspectiva socioevolucionária e naturalista empregada pelo autor, que encara as permanências políticas e morais como resultantes de uma espécie de "teste dos tempos", tende a invalidar as fórmulas muitas vezes coercivas que asseguram essa perpetuação. Em quarto lugar, ao contrário do que pensa o autor, as revoluções não atravessam a história como os relâmpagos atravessam o céu numa tempestade. As ideias revolucionárias só adquirem sentido numa realidade social deteriorada, injusta, desigual, do contrário jamais seriam absorvidas. Nesse sentido, os processos revolucionários, longe de constituírem soluções precipitadas, partem sempre da realidade imediata, geralmente opressora e violenta. A Revolução Francesa, para mantermo-nos fiéis ao exemplo de Coutinho, não pode ser entendida sem que se considere o contexto social responsável por oprimir a maior parte da população francesa (tanto nos campos quanto nas cidades) às vésperas de 1789. Destarte, as revoluções são quase sempre o cume de longos e insustentáveis processos de espoliação e não uma solução irresponsável como quer Coutinho. Se toda revolução é radical, isso se deve ao fato de que a fome, a ausência de liberdade e a existência de privilégios exigem respostas urgentes e não meras soluções paliativas. Aliás, se algo passou pelo "teste dos tempos” foi o caráter revolucionário do ser humano, que nunca se curvou diante das injustiças e desmandos de alguns grupos privilegiados. Em quinto lugar, o autor vê a sociedade como uma espécie de força autônoma, capaz de influir nos rumos tanto dos indivíduos quanto das instituições. Não por acaso, emprega com frequência expressões como "teste dos tempos", "evolução social" ou "contrato entre vivos e mortos" para se referir à capacidade de permanência das tradições, valores e instituições. Há uma deificação completa da sociedade e, consequentemente, o indivíduo é visto como um ser passivo, destituído de sua dimensão histórica. Nesse ponto, em especial, o autor está em franca oposição à concepção marxista de que são os homens fazem história, ainda que não tenham consciência disso. Por último, falta-lhe uma visão mais esclarecedora a respeito do 
Estado, tomado como uma instituição ética, prudente e neutra, capaz de atender as diferentes demandas políticas e sociais. Coutinho simplesmente desconsidera 0 fato de que, numa sociedade como a capitalista, onde predomina a luta de classes, os interesses políticos da burguesia e do proletariado são inconciliáveis. Em outros termos, não há a possibilidade de consensos políticos absolutos, uma vez que 0 grupo que controla o Estado visa sempre atender os seus próprios interesses. Em decorrência da lógica da dominação e das relações de poder (elementos que o autor negligencia completamente), as divergências podem alcançar tal nível de tensão que só pelo uso da força e da violência (seja por parte dos dominadores, seja por parte dos dominados) é possível diminuí-las ou superá-las. Grosso modo, Coutinho dispensa ao conceito de utopia um olhar impreciso, até mesmo superficial. Talvez a leitura do livro de Teixeira Coelho, O que é utopia, pudesse ampliar sua visão acerca do papel concreto, e não abstrato, das utopias no plano político.

\section{Referências}

BRITO, Ênio da Costa. A cultura como desafio. Revista Lumen. São Paulo, v. 6, n. 13, 2000, p. 113-124.

COELHO, Teixeira. O que é utopia. 3. ed. São Paulo, Brasiliense, 1981.

GOERGEN, Pedro. Pós-modernidade, ética e educação. Campinas, Autores Associados, 2001.

Recebido em: 06/05/2014

Aceito em: 10/01/2015

\section{Como citar esta resenha:}

VARES, Sidnei Ferreira de. Conservadorismo e atualidade. Contemporânea - Revista de Sociologia da UFSCar. São Carlos, v. 6, n. 1, jan.-jun. 2016, pp. 259-264. 